\title{
Fracture toughness of RC beams with different shear span
}

\author{
Pavlo Vegera * Rostyslav Vashkevych and Zinoviy Blikharskyy \\ Lviv Polytechnic National University, Department of Building Constructions and Bridges, \\ Karpinskogo Str. 6, Lviv, 79013, Ukraine
}

\begin{abstract}
This article presents the results of experimental investigation of reinforced concrete beams without transverse reinforcement on the shear. In researching, the variable parameter was relative span to effective depth ratio, which acquired the values $\mathrm{a} / \mathrm{d}=2,1.5,1$. The testing program involves testing of each beams samples twice. Beams were tested by the static loading of applied force at two points. Experimental results have shown the difference between the experiments of twin beams above $5-9 \%$. The obtained results indicate an increase of the bearing capacity with a decrease of relative span to the effective depth ratio. The first inclined crack disclosed in mid-height cross section, at the load $50 \mathrm{kN}$ at an angle equal to $45^{\circ}$. With increasing loading, the width of crack increased and the crack propagation occurred to the top surface of the testing sample. On occurrence of limit width of crack $\mathrm{w}_{\max }=0.4 \mathrm{~mm}$, another crack was opened in the direction from the loading point to the edge of beam support. The limit values of the crack opening width are fixed at $71-84 \%$ of the load carrying capacity of the samples. The effect of increasing the shear strength, according to the serviceability, is similar to the increasing of the bearing capacity and close by the value.
\end{abstract}

\section{Introduction}

A large number of buildings and structures are made from the reinforced concrete. Its main advantages are durability and high corrosion resistance of elements. However, it also has significant disadvantages: low tensile strength, application elements of large crosssectional dimensions (in comparison with the steel construction), cracks formation, which lead to corrosion of the reinforcement. For increasing areas of using reinforced concrete, we need to develop and obtain new data about the stress-strain state of reinforced concrete structures.

To analyze the shear stress-strain state we can use the monograph from source [1]. The author highlighted four main stages of development of shear stresses when increasing the transverse force in reinforced concrete beams:

- the first stage: elements work as a solid inelastic body;

- the second stage: in the cross sections, initiating vertical cracks; the tension and compression deformations of concrete are distributed throughout the height of the cross-

\footnotetext{
* Corresponding author: Pavlo.I.Vehera@Ipnu.ua
} 
section, according to the linear regularity, with the maximum values in compressed and stretched concrete fibers;

- the third stage: formation and development of inclined cracks, which leads to a significant change in the strain-strain state of the slope. Developing in the direction of the point of application force, the inclined crack separates the compressed zone into two parts by the height. At the same time, there is an evidently pronounced fracture of the diagram of strain compression at the top of the crack. Deformations of the extremely compressed fiber of the concrete acquire the maximum values in the zone above its vertex.

- the fourth stage: there is a breakdown in the compressed area of concrete as a result of fragmentation or cutting of concrete over the top of the critical crack, or in the stretched zone - as a result of the loss of anchoring with the longitudinal reinforcement. The circuit of stresses in concrete has a curvilinear character, with the maximum value near the compressed face of the element, close to $f_{c k}$.

The bearing capacity of reinforced concrete beams on the shear is influenced by the following factors [2]: the shear distance to effective depth radio, the percentage of reinforcement by transverse and longitudinal rebar, concrete strength and beam height.

In general, under the influence of different combinations of factors mentioned above, three characteristic patterns of destruction of reinforced concrete beams on the shear are distinguished [3]: folding-bending destruction, destruction of the web, destruction owning to infraction anchoring of the longitudinal reinforcement.

Experimental research [4] indicates when reinforced concrete beams loaded with concentrated forces, the key parameter is the distance from the support to the point of load application, when occurrence inclined crack and fracture (shear span). The transverse force that the longitudinal reinforcement perceives is up to $20 \%$ of the transverse force acting in the cross section of the elements having a transverse reinforcement. For elements without transverse reinforcement, it is $7-10 \%$. That is $2-3$ times less than for elements of the reinforced transverse rebar.

In the article [5], the height of the beam changed from 25 to $400 \mathrm{~mm}$ in width $38 \mathrm{~mm}$, while preserving the same percentage of reinforcement. As a result, it was found that the shear strength of samples decreases when the concrete strength decreases, while with increasing percentage of reinforcement - increases, and the value of transverse force, that the longitudinal reinforcement perceives, does not depend on the concrete strength or the percentage of transverse reinforcement.

Researching is carried out with changing diameter of longitudinal reinforcement, number and type of reinforcement (smooth or ribbed) [6]. As a result, it was found that the number of rebar substantially affects the width of the crack opening, the width decreased to $40 \%$, but the effect on the bearing capacity of the shear is insignificant.

The purpose of article [8] is to determine the effect of longitudinal compression and tensile efforts, applied with eccentricity to the shear strength of bending reinforced concrete elements. The studies were carried out at the shear distance to effective depth radio $\mathrm{a} / \mathrm{d}=1,2,3$ for beams with different cross reinforcing, different strength of concrete. The main test factor was the longitudinal force of a positive or negative sign. It is established that the greatest influence is the value of the relative span to effective depth radio (shear span).

Each of the following factors affects the strength and fracture toughness of the shear. As the main parameter, determining the shear stress strain state, is the presence, spread and width of the inclined crack [8], studying the fracture toughness is a topical issue of engineering. 


\section{The testing program}

This article presents the research of the beams without transverse reinforcement. It can happen with the existing beams which have a significant damage of the reinforcement due to corrosion. The testing program involves testing three samples. For research, a technique has been developed for testing each beam twice, which described in our article [9]. All samples are identical sizes; the deviation is less than $2 \%$.

$\mathrm{RC}$ beams were designed the way that the beams destruction took place by shear, according to [10]. To accomplish it, these beams were designed with a significant margin of tensile rebar. This is typical for such studies $[12,13]$.

Beams mark follows BO - beam ordinary, the first digit - serial number, the second digit - prototypes number and the third digit - the section number. For example, BO 1.2-2 means that the tested example from the first series of the second beam of the second section.

Tested beams were $2100 \mathrm{~mm}$ length, $100 \mathrm{~mm}$ width, and $200 \mathrm{~mm}$ height of cross section. As the beam's tension reinforcement, A400C Ø18 mm rebar was chosen, A400C Ø10 mm as compressed reinforcement. Constructive transverse reinforcement - A240C Ø $6 \mathrm{~mm}$ rebar located in the area without transverse force [11].

Concrete of testing beams is $\mathrm{C} 32 / 40$. The variable parameter was relative span to effective depth ratio which acquired the values $\mathrm{a} / \mathrm{d}=2,1.5,1$.

\section{Results of experimental researches}

\subsection{The overview of shear failure of testing beams}

The limit value of concrete compressed deformation at cross section above the inclined crack was taken as the criterion of shear strength (ULS) [10]. The real shear strength of testing elements is the maximum force value observed during the experiment.

The bearing capacity of reinforced concrete beams on the shear strength was for BO 1.1 - $\mathrm{V}_{\mathrm{Ed}}=95 \mathrm{kN}$ (shear span - $\left.\mathrm{a} / \mathrm{d}=2\right)$, BO $1.2-\mathrm{V}_{\mathrm{Ed}}=140.5 \mathrm{kN}(\mathrm{a} / \mathrm{d}=1 / 5)$, for BO $1.3-$ $\mathrm{V}_{\mathrm{Ed}}=198 \mathrm{kN}(\mathrm{a} / \mathrm{d}=1)$ [11]. The obtained results indicate an increase of the bearing capacity with a decrease of relative span to the effective depth ratio. The difference between the experiments of twin beams is $5-9 \%$, which indicates the high reliability of the results and the effectiveness of the proposed research methodology.

All samples were destroyed by shear. The tested samples after testing are shown in Fig. 1 - 3.

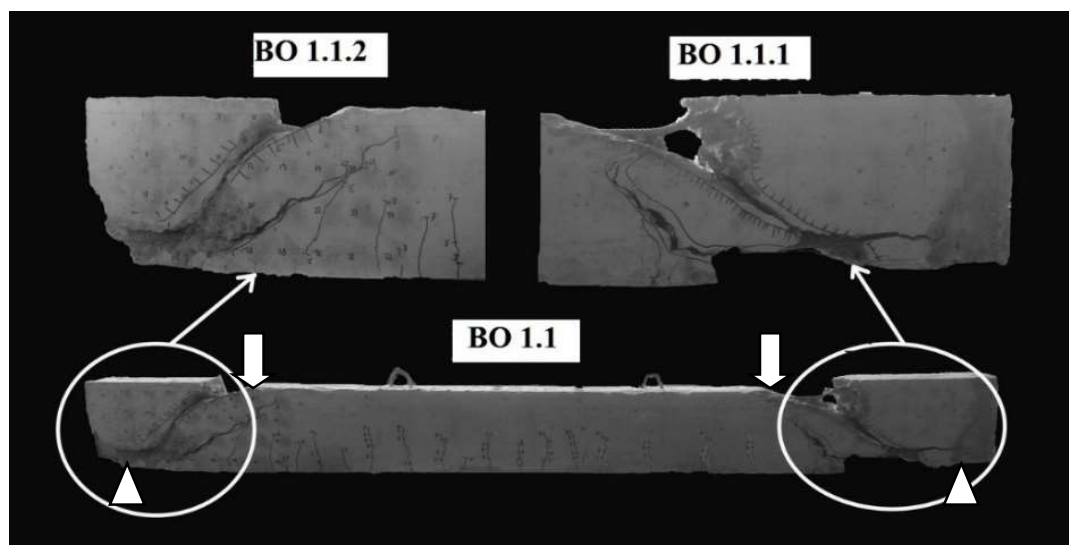

Fig. 1. The tested sample BO 1.1. Shear span $\mathrm{a} / \mathrm{d}=2$. 


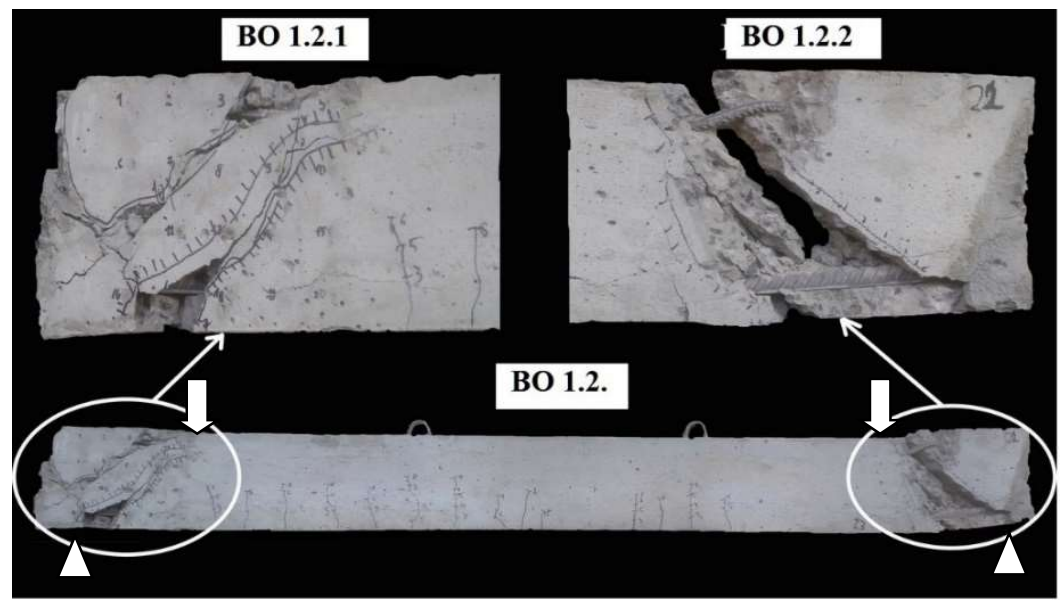

Fig. 2. The tested sample BO 1.2. Shear span $\mathrm{a} / \mathrm{d}=1.5$.

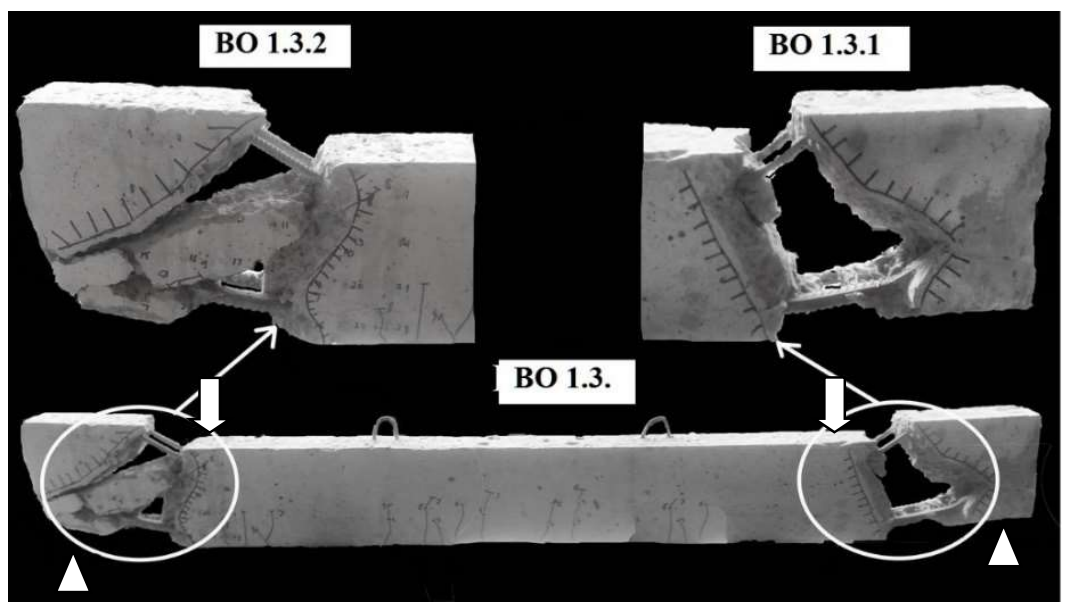

Fig. 3. The tested sample BO 1.3. Shear span $\mathrm{a} / \mathrm{d}=1$.

\subsection{Distribution tensile deformation in the support area}

For each type of test, a contour drawing of deformation distribution in a shear area is made (fig. 4). The deformation and the width of the cracks were taken into account.

For all samples, the following pattern of distribution of deformations in the section is characteristic: tensile deformation in the zone of distribution of an inclined crack, and deformation of compression around them. For beam BO 1.1, the largest tension deformations placed in the middle of the height of the cross section, whereas for beam BO 1.3, which was tested at relative span to effective depth ratio $\mathrm{a} / \mathrm{d}=1$, the maximum deformations are located at the level of tensile reinforcement.

In general, the contour drawing corresponds to the further spread of cracks. 


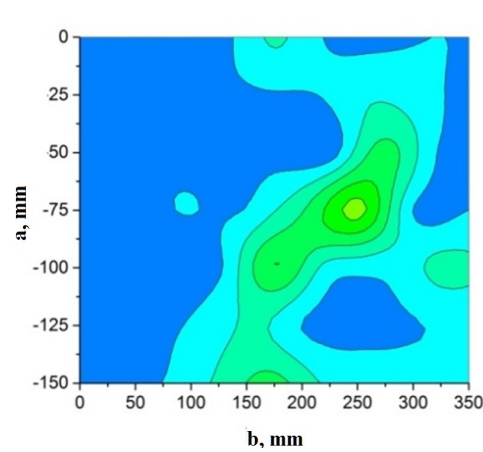

a)

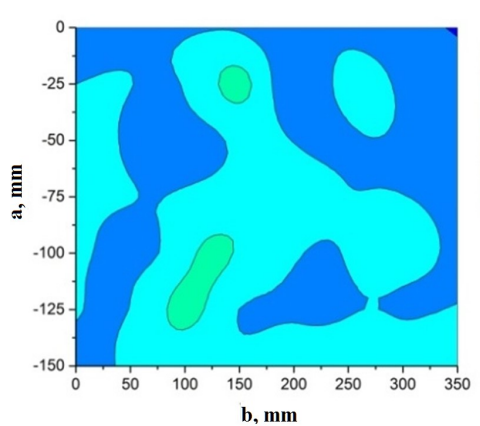

c)

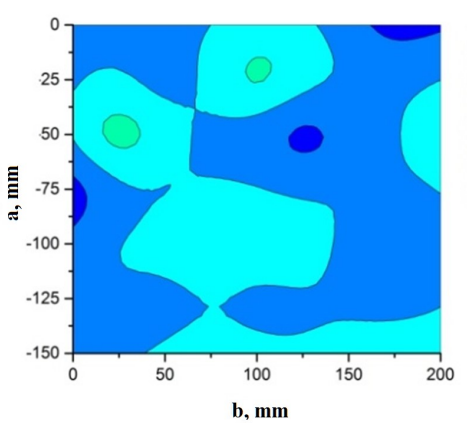

e)

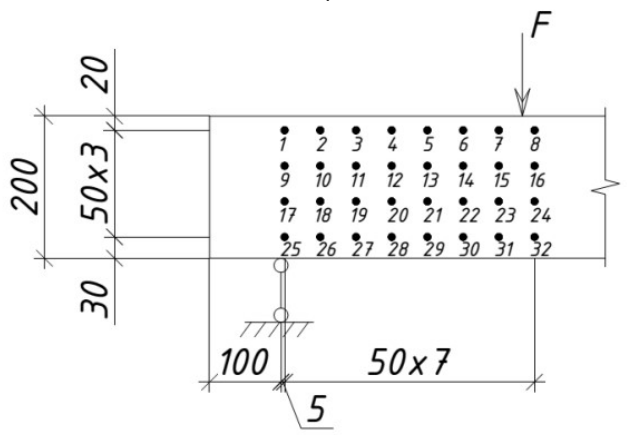

g)

$\mathcal{E}_{\times 10}{ }^{-5}$

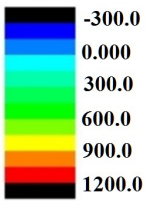

\section{$\mathcal{E}_{\times 10^{-5}}$}

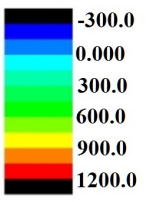

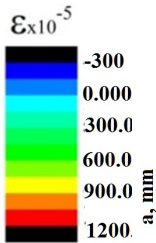

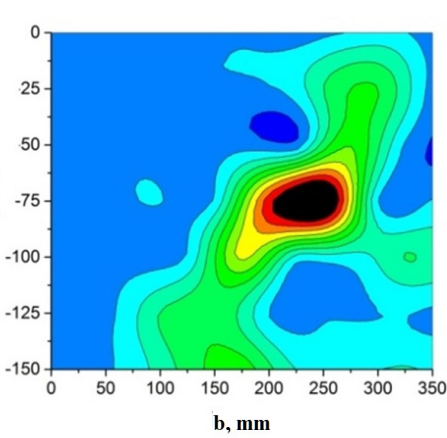

$\varepsilon_{x 10^{-5}}$

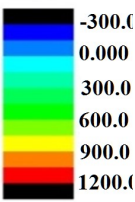

b)

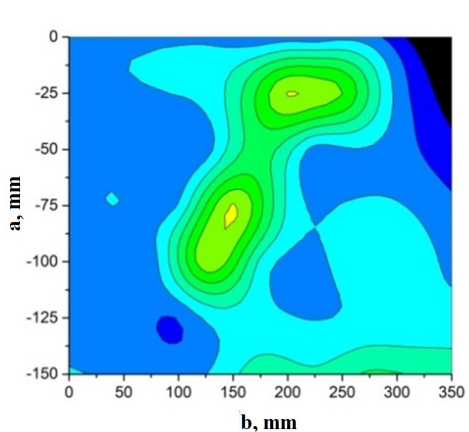

Ex10

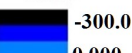

0.000
300.0

600.0

\begin{tabular}{|l|}
\hline 900.0 \\
\hline 1200.0
\end{tabular}

d)

$$
\text { -125 }
$$

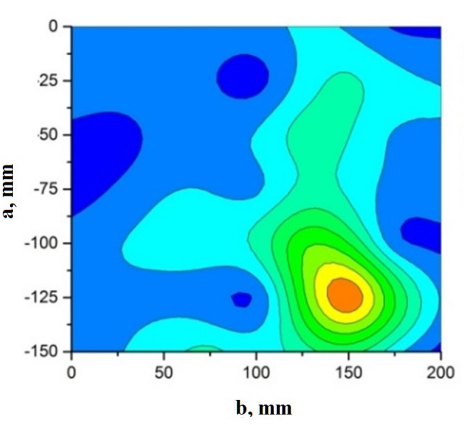

$\varepsilon \times 10^{-5}$

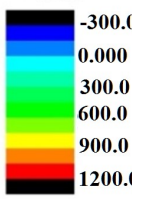

Fig. 4. The distribution of concrete deformation in the shear area:

- before the opening inclined crack:

a) BO 1.1 ; c)BO 1.2 ; e) BO 1.3 ;

- before the exhaustion of bearing capacity:

b) BO 1.1 ; d)BO $1.2 ;$ f) $\mathrm{BO} 1.3$;

g) scheme of measurement points 


\subsection{Fracture toughness in testing samples}

At each stage of the load, we fixed the distribution of cracks, measured the width of the crack opening at the location of the transverse reinforcement, and the average width of the opening shear crack. Measurements were made using a microscope with accuracy $0.05 \mathrm{~mm}$.

The first inclined crack disclosed in mid-height cross section, at the load $50 \mathrm{kN}$ at an angle equal to $45^{\circ}$. At the next stage the inclined crack spread to the bottom surface of the beam. With increasing loading the width of crack increased and the crack propagation occurred to the top surface of the testing sample (Figure 5).

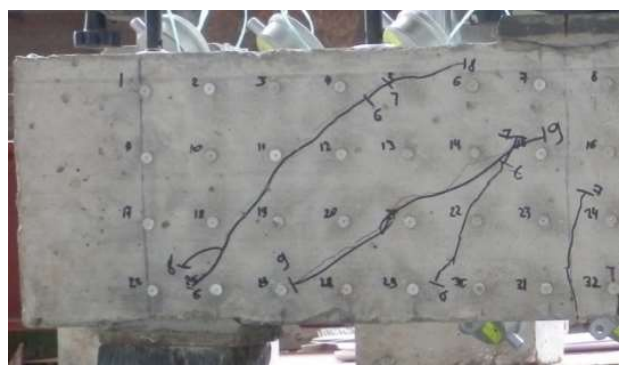

a)

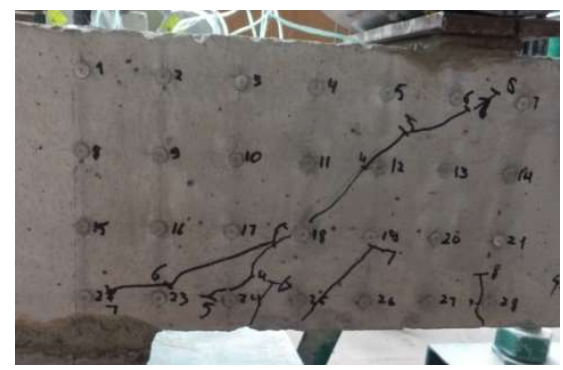

c)

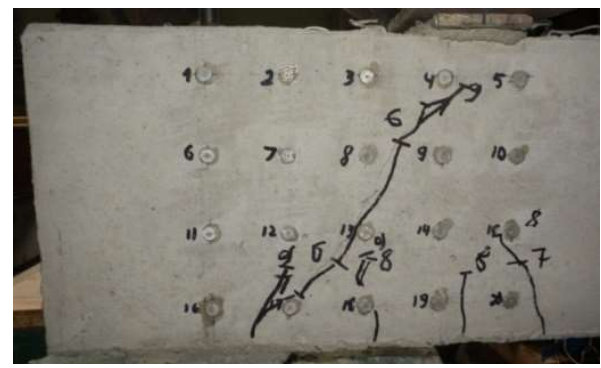

e)

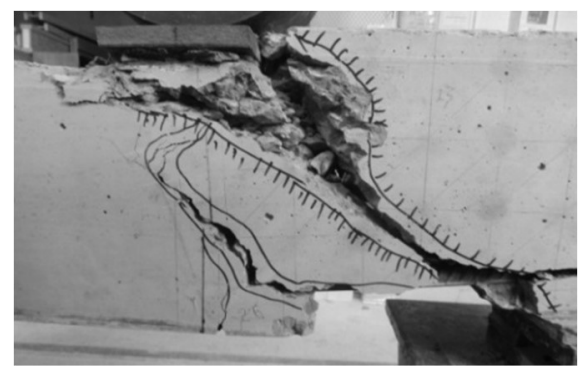

b)

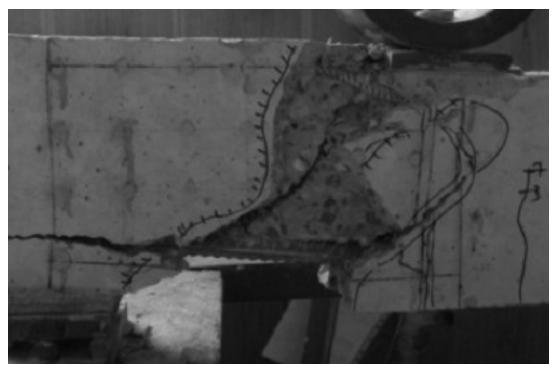

d)

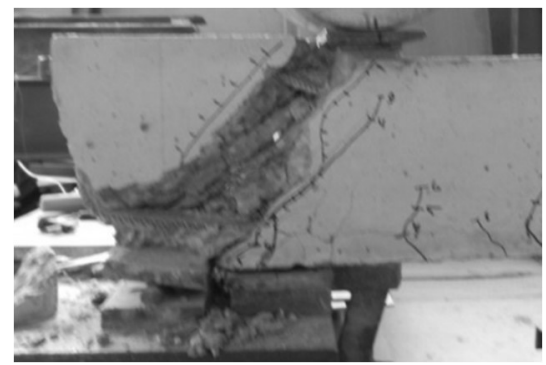

f)

Fig. 5. Distribution of inclined cracks in the sample: a) BO 1.1; c)BO 1.2 ; e) BO 1.3 ; tested samples : b) BO 1.1; d)BO 1.2 ; f) BO 1.3 .

On occurrence of limit width of crack $\mathrm{w}_{\max }=0.4 \mathrm{~mm}[10,14]$, another crack was opened in the direction from the loading point to the edge of beam support. This crack was destructive one. The Inclined crack spread throughout the height of the beam, then occurred the crushing of compressed concrete. Longitudinal tensile reinforcement received typical plastic bending deformations. 
Table 1. The serviceability limit state (SLS) of testing beams on the shear strength.

\begin{tabular}{|c|c|c|c|c|c|c|}
\hline $\begin{array}{l}\text { Types of } \\
\text { the beam }\end{array}$ & $\begin{array}{c}\text { Types of } \\
\text { the } \\
\text { beam's } \\
\text { cross } \\
\text { section }\end{array}$ & $\begin{array}{l}\text { Shear } \\
\text { span } \\
\text { ratio, } \\
\text { a/d }\end{array}$ & $\begin{array}{c}\text { Inclined } \\
\text { crack } \\
\text { width, } \\
\text { mm }\end{array}$ & $\begin{array}{c}\text { Experimental } \\
\text { shear } \\
\text { strength, } \\
V_{E d}^{\text {exp }}, \mathrm{kN}\end{array}$ & $\begin{array}{c}\text { Average } \\
\text { experimental } \\
\text { shear } \\
\text { strength, } \\
V_{E d}^{\text {exp }}, \mathrm{kN} \\
\end{array}$ & $\begin{array}{c}\text { Increasing of } \\
\text { shear } \\
\text { strength, } \\
V_{E d}^{\text {exp }} / V_{E d}^{B O d} 1.1\end{array}$ \\
\hline \multirow{2}{*}{ BO 1.1. } & BO 1.1.1 & \multirow{2}{*}{2} & \multirow{6}{*}{0.4} & 80 & \multirow{2}{*}{80} & \multirow{2}{*}{ - } \\
\hline & BO 1.1.2 & & & 80 & & \\
\hline \multirow{2}{*}{ BO 1.2. } & BO 1.2.1 & \multirow{2}{*}{1.5} & & 120 & \multirow{2}{*}{100} & \multirow{2}{*}{1.38} \\
\hline & BO 1.2.2 & & & 100 & & \\
\hline \multirow{2}{*}{ BO 1.3. } & BO 1.3.1 & \multirow[b]{2}{*}{1} & & 140 & \multirow{2}{*}{150} & \multirow{2}{*}{1.88} \\
\hline & BO 1.3.2 & & & 160 & & \\
\hline
\end{tabular}

As a result of tests, the sample BO 1.1 has reached the limit of operational suitability with the value of the transverse force of $80 \mathrm{kN}$. With a decrease shear span, the serviceability of the $\mathrm{RC}$ beams increased and were for the BO $1.2-1.38$ times and BO $1.3-1.88$ times.

The boundary values of the crack opening width are fixed at $71-84 \%$ of the load carrying capacity of the samples (Table 2).

Table 2. The comparison of testing beams on the shear strength.

\begin{tabular}{|c|c|c|c|c|c|c|}
\hline $\begin{array}{l}\text { Types of } \\
\text { the beam }\end{array}$ & $\begin{array}{l}\text { Types of } \\
\text { the } \\
\text { beam's } \\
\text { cross } \\
\text { section }\end{array}$ & $\begin{array}{c}\text { Shear } \\
\text { span } \\
\text { ratio, } \\
\text { a/d }\end{array}$ & $\begin{array}{c}\text { Inclined } \\
\text { crack } \\
\text { width, } \\
\text { mm }\end{array}$ & $\begin{array}{c}\text { Average } \\
\text { experimental } \\
\text { shear } \\
\text { strength, } \\
V_{E d}^{\text {exp }}, \mathrm{kN}\end{array}$ & $\begin{array}{c}\text { Average } \\
\text { experimental } \\
\text { shear } \\
\text { strength by } \\
\text { SLS, } \\
V_{E d}^{s l s}, \mathbf{k N}\end{array}$ & $\begin{array}{c}\text { Increasing } \\
\text { of shear } \\
\text { strength, } \\
V_{E d}^{S L S} / V_{E d}^{\text {exp }}\end{array}$ \\
\hline \multirow{2}{*}{ BO 1.1. } & BO 1.1.1 & \multirow{2}{*}{2} & \multirow{6}{*}{0.4} & \multirow{2}{*}{95} & \multirow{2}{*}{80} & \multirow{2}{*}{0.84} \\
\hline & BO 1.1.2 & & & & & \\
\hline \multirow{2}{*}{ BO 1.2. } & BO 1.2.1 & \multirow{2}{*}{1.5} & & \multirow{2}{*}{140.5} & \multirow{2}{*}{100} & \multirow{2}{*}{0.71} \\
\hline & BO 1.2.2 & & & & & \\
\hline \multirow{2}{*}{ BO 1.3. } & BO 1.3.1 & \multirow{2}{*}{1} & & \multirow{2}{*}{198} & \multirow{2}{*}{150} & \multirow{2}{*}{0.76} \\
\hline & BO 1.3.2 & & & & & \\
\hline
\end{tabular}

Using the limit crack opening width as criteria of exhaustion of the bearing capacity (SLS) we saw that remains about $16-29 \%$ before the danger of shear failure of the beam.

The effect of increasing shear strength by SLS is similar to the increasing of the bearing capacity and close by the value. Value of measuring maximum crack opening is described in the table 3 .

Table 3. Maximum inclined crack opening width of testing beams

\begin{tabular}{|c|c|c|c|c|c|}
\hline $\begin{array}{l}\text { Types of the } \\
\text { beam }\end{array}$ & $\begin{array}{l}\text { Types of the } \\
\text { beam's } \\
\text { cross section }\end{array}$ & $\begin{array}{c}\text { Shear span, } \\
\text { a/d }\end{array}$ & $\begin{array}{c}\text { Shear } \\
\text { strength, } \\
V_{E d}, \mathrm{kN}\end{array}$ & $\begin{array}{c}\text { Inclined } \\
\text { crack width, } \\
\text { mm }\end{array}$ & $\begin{array}{c}\text { Average } \\
\text { inclined } \\
\text { crack width, } \\
\text { mm }\end{array}$ \\
\hline \multirow{2}{*}{ BO 1.1. } & BO 1.1.1 & \multirow{2}{*}{2} & 90 & 0.8 & \multirow{2}{*}{0.85} \\
\hline & BO 1.1.2 & & 90 & 0.9 & \\
\hline \multirow{2}{*}{ BO 1.2. } & BO 1.2.1 & \multirow{2}{*}{1.5} & 130 & 0.7 & \multirow{2}{*}{0.65} \\
\hline & BO 1.2.2 & & 130 & 0.6 & \\
\hline \multirow{2}{*}{ BO 1.3. } & BO 1.3.1 & \multirow{2}{*}{1} & 190 & 0.6 & \multirow{2}{*}{0.55} \\
\hline & BO 1.3.2 & & 190 & 0.5 & \\
\hline
\end{tabular}

It should be noted that in all samples, the limit crack occurs shortly before the exhaustion of the bearing capacity on the shear. However, the maximum values of 
inclined cracks width is fixed at the value of $0.55-0.85 \mathrm{~mm}$. This indicates a rapid increase cracking width after the samples loss their serviceability. When the shear span decreases the width of the crack opening decreases also.

\section{Conclusion}

Based on the data above, the following conclusions can be drawn:

1. Fracture toughness of RC beams increases with a decrease of span to the effective depth ratio. Results are comparable with the increasing of bearing capacity.

2. The first inclined crack disclosed in mid-height cross section at the load $50 \mathrm{kN}$ at an angle equal to $45^{\circ}$ and it does not depend on the shear span.

3. The maximum width of inclined cracks decrease with decreasing shear span. The maximum values of width of inclined cracks are fixed at the value of $0.55-0.85$ $\mathrm{mm}$.

4. Using the limit crack opening width as criteria of exhaustion of the bearing capacity (SLS) we saw that remains about $16-29 \%$ before the danger of shear failure of the beam.

\section{References}

1. A. Zalesov, Yu. Klimov, Strength of reinforced concrete structures under the action of transverse forces, 105 (1989)

2. A.H. Nilson, D. Darwin, C. W. Dolan, Design of concrete structures, (2003)

3. F. Leonardt, R. Walter, Beton-und Stalhbetonbau 8, (1962)

4. O.O. Dovjenko, T.Yu. Kachan, O.O. Malyovana, V.Yu. Borbych, BC 78, 565 (2013)

5. Z.P. Bazant, M.T. Kazemi, ACI 88(3), 268 (1991)

6. B. Sing, S. Cnintakindi JSTBU 166, 257 (2015)

7. V.S. Dorofeyev, V.M. Karpyuk, O.M. Krantovska, M.M. Petrov, SCTP 755, 118 (2013)

8. L.O. Doroshkevych,. Ye.I. Kryvyi Transport Academy of Ukraine, 240 (2001)

9. P. Vegera, R. Khmil, Z. Blikharskyy SCTP 823, 38 (2015)

10. National Standard of Ukraine, Concrete and reinforced concrete structures: DBN B.2.6 - 98: 2009, 84 (2011)

11. P. Vegera, R. Vashkevych, R. Khmil, Z. Blikharskyy SSP 12 (2), 39 (2017).

12. A. Alzate, A. Arteaga, A. de Diego, D. Cisneros, R. Perera, MC 63(310), 251 (2013)

13. E. David, C. Djelal, F. Buyle-Bodin, 2nd Int. PhD Symposium in Civil Engineering, 1 (1998)

14. Eurocode 2: Design of concrete structures - Part 1-1: General rules for buildings. EN 1992-1-1:2004 (E), 225 (2004) 